\title{
An integrative view of the pandemic in Apollo's Arrow: The Profound and Enduring Impact of Coronavirus on the Way We Live
}

\author{
Uma visão integrativa da pandemia em Apollo's Arrow: \\ The Profound and Enduring Impact of Coronavirus \\ on the Way We Live
}

Una visión integradora de la pandemia en Apollo's Arrow:

The Profound and Enduring Impact of Coronavirus

on the Way We Live

\begin{abstract}
APOLLO'S ARROW: THE PROFOUND AND ENDURING IMPACT OF CORONAVIRUS ON THE WAY WE LIVE. Christakis NA. New York: Little, Brown Spark; 2020. 384 p. ISBN: 9780316628211.
\end{abstract}

doi: 10.1590/0102-311X00016021

A comprehensive approach to the COVID-19 pandemic requires researchers to have a deep understanding of different scientific fields that dialogue with each other to provide explanations, advance knowledge, and propose practical solutions to the countless global challenges that have emerged ever since the crisis outbreak, in late 2019. In his book Apollo's Arrow: The Profound and Enduring Impact of Coronavirus on the Way We Live, physician and sociologist Nicholas A. Christakis, a Professor at Yale University (United States), outlines an integrative scenario of the COVID-19 pandemic using his expertise in different areas of knowledge, such as epidemiology, medicine, history, sociology, psychology, and genetics.

Besides referencing numerous scientific papers, Christakis also uses other information sources, such as newspapers and general magazines articles, to illustrate the different spheres of life affected by the coronavirus worldwide. The author analyzes the COVID-19 pandemic considering the accumulated historical knowledge about pandemics, epidemics, and past outbreaks such as the Spanish flu, Black Death, smallpox, and the 2003 SARS coronavirus pandemic. Although mainly focused on the American society, his analysis convenes discussions and reflections applicable to specific situations in different countries, including Brazil.

The Brazilian context exhibits many peculiarities regarding adherence to social distance and other non-pharmacological interventions 1, the pandemic evolution across regions 2 , its impacts on the national economy and labor market 3 , and even the effects on mental health and interpersonal relationships during this period 4 . In this sense, Christakis' work may propose possible alternatives to address the particular issues emerging from the pandemic in Brazil.

The book is organized into eight chapters that cover a range of subjects related to the pandemics, from the probable origins of SARSCoV-2 to the short, middle, and long-term developments of the pandemics, as well as their possible outcomes. Chapter 1 discusses the emergence of the virus in China, in late 2019, and its trajectory from community to global transmission. The author also reports the first public health decisions made in China and some genetic characteristics of the pathogen.

Chapter 2 compares the current pandemic with past pandemics, especially that of 2003 , also caused by a coronavirus (SARS-1). The author also presents specific epidemiological features of SARS-CoV-2, namely: infection fatality rate, 
case fatality rate, basic infection reproduction number (R0), and effective reproduction number (Re or Rt).

Chapter 3 discusses interventions in response to the coronavirus pandemics, in particular non-pharmacological interventions. For that, Christakis offers examples of the COVID-19 pandemic as well as of past pandemics, including individual (hygiene practices, wearing masks, and social distancing) and collective interventions (closing borders and schools, controlling gatherings in public spaces, testing and tracking cases). Although devoid of the technological resources that we have today, authorities from past historical periods likewise endeavored to implement measures related to all these spheres of life to contain other pandemics.

Chapter 4 addresses the psychological and behavioral aspects of the pandemics. The author explores a set of feelings and behaviors associated with the pandemic scenario, such as sadness, fear, denial, and lies. Besides that, this section also discusses the prejudices related to the origins of the coronavirus or to the characteristics of the most vulnerable groups in different outbreaks and pandemics, such as race/ethnicity, religion, and sexual orientation. Christakis also addresses how disinformation can affect feelings and behaviors in both the individual and collective sphere.

Chapter 5 deals with the division "us versus them" that may emerge in pandemic settings. Despite recognizing the widely spread optimistic idea that the coronavirus pandemic could equalize or balance inequalities, the author lists a series of social divisions based on age, gender, and socioeconomic status that may arise during this period. These factors may not only exacerbate existing dichotomies, but also create new ones, such as those who can work from home versus those who cannot; those who follow preventive recommendations versus those who do not; and those already immune to the virus versus those who are not.
If the pandemic scenario can exacerbate existing social divisions, it can also stimulate behaviors related to altruism, solidarity, empathy, cooperation, and generosity - as shown in Chapter 6 . Besides these positive aspects, Christakis highlights individuals' ability to learn and teach based on human cumulative culture and experience, focusing on social learning through observation and imitation. Such learning approach allows the individual and society to cope with the pandemic based on an accumulated knowledge that can be shared through books, courses, and online content. Likewise, prior scientific knowledge expands the possibilities for scientific collaboration and enables rapid developments of studies approaching the genetics of the SARSCoV-2 and pharmacological treatment alternatives, such as vaccines and medicines.

Chapter 7 addresses the changes arising from the pandemic and its impacts on individual and collective attitudes in the immediate, intermediate, and post-pandemic periods. Changes at the individual level include aspects such as the way of greeting others (due to preventive measures) and an increase in religion-related behaviors and beliefs. As for the social and collective level, changes in medical and healthcare fields, the market and working dynamics, teaching and learning methods within schools/universities, and the role of science in responding to social demands can have lasting effects, transcending the post-pandemic period.

Also based on the history of previous pandemics, the last chapter of the book is dedicated to the probable "end" of the coronavirus pandemic. According to Christakis, the global impact of this health crisis may increase the baseline risk of death for all individuals, of any age (considering data from the United States). This would imply years of life lost in the overall population, besides resulting in major economic impacts. After its abrupt appearance, SARS-CoV-2 will likely become endemic and continue to circulate in lower levels among humans, probably 
with milder effects due to mutations. The author states that coping with the pandemic requires both biological and social tools, and he believes that herd immunity can be achieved either naturally or through vaccination by 2022 or after.

The book as a whole presents contributions from various branches of scientific knowledge that help understanding the novel coronavirus pandemic, reaching readers with many different backgrounds. Christakis intersperses scientific data with reports of daily life changes that have affected everyone experiencing the effects of the pandemic, so that the general public can also benefit from reading.

Lucas Cordeiro Freitas 1

1 Universidade Federal de São João del-Rei, São João del-Rei, Brasil.

lcordeirofreitas@ufsj.edu.br

\section{Additional information}

ORCID: Lucas Cordeiro Freitas (0000-0002-38609327).

1. Garcia LP, Duarte E. Intervenções não farmacológicas para o enfrentamento à epidemia da COVID-19 no Brasil. Epidemiol Serv Saúde 2020; 29:e2020222.

2. Ranzani OT, Bastos LSL, Gelli JGM, Marchesi JF, Baião F, Hamacher S, et al. Characterisation of the first 250,000 hospital admissions for COVID-19 in Brazil: a retrospective analysis of nationwide data. Lancet Respir Med 2021; 9:407-18.

3. Costa SS. The pandemic and the labor market in Brazil. Rev Adm Pública 2020; 54:969-78.

4. Freitas LC, Del Prette ZAP, Del Prette A. Social distancing in the COVID-19 pandemic: notes on possible impacts on the social skills of individuals and populations. Estud Psicol (Natal); in press.
Submitted on $21 / \mathrm{Jan} / 2021$

Final version resubmitted on 01/Mar/2021

Approved on 04/Mar/2021 